\title{
Erratum to: Time-domain BEM for transient interfacial crack problems in anisotropic piezoelectric bi-materials
}

\author{
Jun Lei · Chuanzeng Zhang
}

Published online: 3 April 2012

(C) Springer Science+Business Media B.V. 2012

\section{Erratum to: Int J Fract \\ DOI 10.1007/s10704-012-9686-2}

The definition of $\beta=-\sqrt{\left|\left(a_{5} f_{12}+a_{6} f_{13}\right) /\left(v_{11} a_{1}\right)\right|}$ under the Eq. (42) should be substituted by ' $\beta=$ $-\sqrt{\left|\left(a_{5} f_{12}+a_{6} f_{13}\right) /\left(v_{11} a_{1}\right)\right|}$ for $b>0$ and $\beta=$ $-i \sqrt{\left|\left(a_{5} f_{12}+a_{6} f_{13}\right) /\left(v_{11} a_{1}\right)\right|}$ for $b<0$.'

The online version of the original article can be found under doi:10.1007/s10704-012-9686-2.

\section{J. Lei (西)}

Department of Engineering Mechanics, Beijing University of Technology, Beijing 100124, People's Republic of China e-mail: leijun@bjut.edu.cn

C. Zhang

Department of Civil Engineering, University of Siegen,

57076 Siegen, Germany 